\title{
Micro Cup Drawing without Wrinkles Using a Bulged Punch
}

\author{
Syamsul Hadi ${ }^{1, \mathrm{a},}$, Anh Kiet Tieu ${ }^{2, \mathrm{~b}}$, Cheng Lu ${ }^{2, \mathrm{c}}$, Hailiang Yu ${ }^{2, \mathrm{~d}}$, Alain Kusmoko ${ }^{2, \mathrm{e}}$, \\ Anggit Murdani ${ }^{1, \mathrm{f}}$, and Dianta Ginting ${ }^{3, \mathrm{~g}}$ \\ 1 Department of Mechanical Engineering, State Polytechnic of Malang, Malang 65141, Indonesia \\ 2 School of Mechanical, Materials, Mechatronics, and Biomedical Engineering, University of Wollongong, \\ Wollongong 2520, Australia \\ 3 Department of Applied Physics and Institute of Natural Sciences, Kyung Hee University, South Korea \\ E-mail: a, ${ }^{*}$ syamsul.hadi@polinema.ac.id, asyampol2003@yahoo.com (Corresponding author), \\ bktieu@uow.edu.au, ccheng_lu@uow.edu.au, dhailiang@uow.edu.au, ealainkusmoko@gmail.com, \\ fanggitmurdani@yahoo.com, gdianta24111982@yahoo.com
}

\begin{abstract}
A novel Bulged Punch (BP) was successfully performed for wrinkle elimination in micro cup drawings of AA1235 foils. BP was used to create a specific enlarged gradual punch profile before wrinkles began to occur until the end of the stroke, with fully annealing of AA1235 occurring before accumulative roll bonding (ARB), asymmetric rolling (AR), and stress relieving of a rolled blank, and deep drawing. The research purpose is to create a micro cup without wrinkles. The method was studied via experimentally deep drawing a blank thickness of $300 \mu \mathrm{m}$ with pairs of dies-BPs supported by a press tool. Blanks were processed under (a) ARB 4 and 6 cycles, (b) combined ARB with AR and (c) post-heat-treatment. The process was selected when a force (F) from the simulation matched with the measured value. The results showed that BP can simultaneously eliminate the occurrence of wrinkles at the cup edge, reduce the earing occurrence, increase cup corner thickness, and decrease the edge thickness. Simulation models were built using the finite element method software LS Dyna, which supports experimental evidence. The findings imply that BP can successfully eliminate wrinkles at the cup edge.
\end{abstract}

Keywords: Wrinkle elimination, cup drawing, AA1235 foils, bulged punch, simulation.

ENGINEERING JOURNAL Volume 25 Issue 12

Received 7 May 2021

Accepted 19 December 2021

Published 30 December 2021

Online at https://engj.org/

DOI:10.4186/ej.2021.25.12.51 


\section{Introduction}

Deep drawing is one of the most needed microforms. In deep drawing, product defects often occur in the form of tearing and wrinkling. Sridhar et al. [1] mentioned that wrinkling is a major type of deep drawing failure. Bell et al. [2] stated that hydroforming technology can reduce wrinkling and can make components lighter, stiffer, and cheaper with less waste. Rejection of the components of the deep-drawing results needs to be predicted such as by Takalkar and Chinnapandi [3] from thinning, wrinkling and spring back. Progressive micro forming techniques, especially size effect deformation in materials, dimensional accuracy, deformation load, failure analysis, the roughness of micro components (deep drawing, extrusion, forging, incremental forming, and stamping) which are the research issues of micro mass production and industrial complexity require extensive attention according to Srinivasan, Rajenthirakumar and Sridhar [4].

Wrinkling was investigated in the cone cup wall area with simulation and hydrodynamic experiments through radial pressure with an inward flowing fluid which showed a reduction in wrinkling according to Khademi et al. [5] but did not eliminate wrinkling.

In cases of cup wall wrinkles, tearing in the radius of punch (RP), cup edge earing, tears beginning to occur at $\mathrm{RP}$, the cup edge thickening compared to the initial thickness of blank (TB), and difficulty of ejecting the cup is due to cup edge thickening frequently occurs in a micro cup drawing. Research regarding wrinkle elimination in micro drawings using a BP (bulged punch) is significant since cup wrinkles always occur in a micro drawing. Producers of micro part products will there derive the benefits of the research.

The effect of the initial foil thickness and reduced blank form was investigated by Mahmood, Irthiea and Ahmed [6] for deep drawing on SS304 square cups which showed that results without flanges.

Preparation made by Lubis and Ristiawan [7] in blank materials was reached a good higher value for a $2.5 \%$ clearance (between die and punch) which over a $50 \%$ shear zone, compared to a $5 \%$ clearance that reached a 20 to $48 \%$ shear zone.

Residual stresses in blank sheets are generally removed through annealing or stress relief so that residual stresses do not cause tearing during deep drawing. Another method was researched by Pan et al. [8] with $1.5 \%$ cold rolling on AA7 $\mathrm{xxx}$ T-section panels to eliminate residual stresses in the quenched core components up to $<83 \mathrm{MPa}$. An AC8H Aluminum alloy was observed by Akhtar et al. [9], who found that after quenching from 530 to $60^{\circ} \mathrm{C}$, the alloy was heated to an aging temperature when heated at 150 and $175^{\circ} \mathrm{C}$, and the maximum strength was reached but decreased when heated at $200^{\circ} \mathrm{C}$.

The manufacturing of aluminum foil lamination by a combination of accumulative roll bonding (ARB) followed by asymmetric rolling (AR) can increase the strength and ductility because the microstructure is not homogeneous with nanoscale granules and abnormal hardening of some grains occurs during AR according to Yu et al. [10].

Several studies related to deep drawing have been conducted by Hadi et al. [11], Hadi [12], Mahmood, Irthiea and Abed [13], Dhal, Panigrahi and Shunmugam [14], Takalkar and Babu [15], Luo et al. [16], Wang et al. [17], Sato et al. [18], and Thanh et al. [19] regarding cup form-ability, wrinkles, reducing earing, thickening, flexible deep drawing, hydromechanical deep drawing, forming limit diagram (FLD) and limiting drawing ratio (LDR) which have shown progress. The AA1235-H14 flow stress with a thickness of $16-300 \mu \mathrm{m}$ is significantly reduced by thinning as a function of the thickness and grain size of the material. An LDR of 2.003 can be achieved via ARB followed by stress releasing (SR) which increases the cup form-ability due to planar anisotropy being reduced and normal anisotropy increasing in the research of Hadi et al. [11]. Simulations using LS Dyna without wrinkles were achieved with a $300 \mu \mathrm{m}$ blank thickness, and 14 and $15 \mathrm{~mm}$ blank diameters. Wrinkles began to appear at the cup edge for a $130 \mu \mathrm{m}$ blank thickness, with increasingly wrinkles for a $70 \mu \mathrm{m}$ blank thickness. The results of the experiments and simulations using BP for the first time by showed advantages: prevention of wrinkles, reducing earing, thickening the wall thickness at the cup corner radius which reduces tears, and thinning the thickness of cup edge based on research results from Hadi [12]. Floating rings drawing deep on SS304 micro cups as a flexible pad on a flexible die placed between a blank sheet and a rubber pad are worth adopting in the research of Mahmood, Irthiea and Abed [13]. To overcome the abnormal stress-strain of the material, refined grains were used by Dhal, Panigrahi and Shunmugam [14] in the deformation zone with cryogenic rolling followed by annealing to a fully recrystallized, equiaxed, strain-free refined microstructure to increase the limits of microforming capabilities. Multistage deep drawing sequences for the first stage with a flat bottom and the second stage with a bulge bottom were simulated by Takalkar and Babu [15], who used that the strain distribution is used to produce FLD to predict thinning and wrinkling. Micro-hydromechanical deep drawing (MHDD), demonstrated by Luo et al. [16], revealed that the wrinkled area causes significant wear on the cup wall due to heavy contact between the blank and die. Experiments on a micro deep drawing of annealed of T2 copper foils were reached a maximum LDR of 2.2 with a $50 \mu \mathrm{m}$ thickness of blank and a $0.5 \mathrm{~mm}$ diameter of the punch according to the research by Wang et al. [17]. Sato et al. [18] stated that MHDD requires a high counter pressure of $\geq 100 \mathrm{MPa}$. Intarakumthornchai et al. [19], through hydromechanical deep drawing (HDD) have obtained optimal results of $\mathrm{BHF}$ and linear pressure profiles of a parabolic cup with the response surface method (RSM) in minimizing part thinning of the cup without cracks and wrinkles. 
Thanh et al. [20], conducted a study on a deepdrawing using a double-action hydraulic press for SPCC steel (JIS G3141) fuel-filter cup with first-second punches and the dies were examined to optimize the geometric parameters (BHF/blank holder force, dieshoulder radius, and clearance) to ensure thickness uniformity. The die-shoulder radius was the most influential parameter in the occurrence of wrinkling and tearing.

Some research by Reddy and Rajesham [21], Shinge and Debade [22], Sudarsan et al. [23], Sheng and Mallick [24], and Woo et al. [25] has been conducted regarding LDR and FLD in the deep drawing, which shows that the prediction between the experiment and the simulation is close enough, the safe working zone and fracture zone, change in strains, and the ductile failure criterion (DFC) is met. Research related to LDR has been conducted on two undersize blanks and one of the oversize blanks with experiments and simulation, and the results are in good agreement with the $5.4 \%$ variation which is likely due to lubrication conditions specified by Reddy and Rajesham [21]. Shinge and Debade [22] have manufactured FLD from HCHCr steel (ASTM E 221802) with a $5 \mathrm{~mm}$ diameter grid, and showed that the area below the FLD was the safe working zone, and the above FLD was a fracture zone with a major strain of $13.1-36.78 \%$ and minor strain $1.06-6.64 \%$. Sudarsan et al. [23] evaluated of SS304 sheets with a $200 \mu \mathrm{m}$ thickness for FLD through limiting dome height (LDH) tests with different widths of the rectangular specimens using a hemispherical punch of $30 \mathrm{~mm}$ and found that the change in marginal in limiting strains attributable to the change in the diameter of the punch from 30 to $50 \mathrm{~mm}$, $\mathrm{FLD}_{0}$ (at 0 degrees of rolling direction) changed by approximately $7.5 \%$ in the punch diameter and $6.8 \%$ changed in the stretching direction, and the change in the diameter of the circular grid from 2.5 to $2.0 \mathrm{~mm}$ resulted an increased in $\mathrm{FLD}_{0}$ by $15 \%$. DFC treats decentralized necking as a critical and failure damage as a function of the thickness of the initial sheet and strain path to predict FLD by validating 16 different steel and aluminum sheets, whose formulation shows sufficiently matching in most empirical cases, as proved by Sheng and Mallick [24]. The FLD for the Al 6061-T6 sheet improved the form-ability at a high-speed forming and the experimental FLD results for the electro-hydraulic forming (EHF) freebulging test were shown to be in good agreement with the theoretical FLD according to the research of Woo et al. [25]. An experimental-theoritical investigation was conducted by Zhalehfar, Hashemi and Hosseinipour [26] on the effect of the strain path change on the FLD of AA5083 sheets on the form-ability with a hemispherical punch. There was a good agreements between the theoretical results and experimental observations. An evaluation was conducted by Rahmatabadi and Hashemi [7] on AA1050 on the elongation and FLD values after annealing at $380^{\circ} \mathrm{C}$ for 60 minutes is decreasing from $34 \%$ and $23 \%$ to $3.5 \%$ and $5 \%$ in 1 cycle of ARB, respectively. However, when increasing up to 7 cycles ARB, the elongation and FLD values were increased to $7.8 \%$ and $14.5 \%$, respectively, and when compared to the annealed samples the values were decreased to $77 \%$ and $37 \%$, respectively. Alisaraei et al. [28] experimentally studied AA 1050 from $200 \mu \mathrm{m} \times 300 \mathrm{~mm} \times 80 \mathrm{~mm}$ samples for 5 cycles of ARB and obtained an ultimate tensile strength (UTS) $393 \mathrm{MPa}$ or $5.9 \mathrm{x}$ larger than that of the initial sample which was influenced by 2 mechanisms of strain hardening and grain refinement.

Micro deep drawing simulations with various eccentric distances and thicknesses were conducted: if the thickness was almost the same as the punch and die gap, it tended to experience fractures at the cup corner on the bottom side; if the gap was much wider than the thickness, wrinkling appeared; if the thickness was decreased, the wrinkles approached the bending zone; and if the die-punch eccentricity increased, the press resulted in a faulty product. The results can be compared to fit with the results of experiments by Hadi et al. [29]. Simulations for ironing in flanging of DC04 sheets with a thickness of $1.75 \mathrm{~mm}$ were used to predict the springback effect in the element formulation in new thick shell showing that an increase in the element can acquire a high accuracy material flow with maximum errors from thickness or cup heights is $<5 \%$, but errors in hard ironing cases reach $45 \%$, the results are in agreement with the experiment based on the results of the investigation by Güner et al. [30].

A $90 \mu \mathrm{m}$ brass sheet was used to plot FLD using the LDH test according to ASTM E2218-02, and the results of hemispherical punch with a $15 \mathrm{~mm}$ diameter were plotted. Research and analytical approaches showed that the research was more accurate and had a safe zone with a higher accuracy than the analytical approach as proven by Mashalkar, Kakandikar and Nandedkar [31].

Micro deep drawing of Fe-30Mn-3Si-2Al-0.11C steel for domed-bottom cups with different grain sizes and thicknesses showed that earing easily occurs with the larger grain sizes and smaller thickness in the cups of good-formed domed-bottom. If the fraction of the grain boundaries increases with a smaller grain size, than the deformation load will increase. The case were earing becoming intense of a larger grain size is a result of characterization by Guo, Sun and Fu [32].

Micro deep drawing simulation on SUS304 sheets in which friction and contact significantly impact microsheet forming and its homogeneity cannot be simplified, since they show different roughening behavior at three areas (wall, radius, bottom) on the drawn cup, as observed by Luo, Jiang and Wei [33]. Cylindrical cups with an $8 \mathrm{~mm}$ inner diameter were formed with a rigid punch and polymer powder flexible forming (PPFF) deep drawing. An annealed blank thickness of $0.4 \mathrm{~mm}$ at $450^{\circ} \mathrm{C}$ for $1 \mathrm{~h}$ from Copper $\mathrm{C} 1100$ was produced wellformed cups using PVC powder to obtained an LDR = 2.1, which was higher than the rigid punch observed by Zhang and Gong [34]. Deep drawing DC04 sheets (EN 10130:2009) were used in pulling off a sheet on the draw bead, in which the effectiveness of reducing the friction 
coefficient depends not only on the lubricant but also on the level of deformation on the middle roll displacement. An increase in the specimen width causes an increase in the friction coefficient, which is the result of the evaluation by Trzepiecinski, Fejkiel and Kubit [35].

The influence of the draw bead geometry utilized on the mechanical properties shows that the TS is enhanced by approximately $25 \%$ for materials of DC0 4 and $4 \%$ for DP800 when the fracture strain is decreased by $>70 \%$ for DC04 and 40\% for DP800, which is the experimental result of Schmid and Merklein [36]. The DC04 after tensile testing has a $25 \%$ increase in TS, but the fracture strain can reach $>70 \%$ which shows a weakness compared to DP800 whose fracture strain is $40 \%$, so with similar forming conditions between the draw bead and deep drawing can indicate that the form-ability of DP800 is better than that of DC04. The restraining force increases slightly when the DC04 sheet thickness increases as a consequence that of the material flowing through the draw bead which results in the sheet metal experiencing work hardening and wall thinning for higher restraining forces, these results are the experimental results of Bassoli et al. [37]. DC04 and DP800 with a thickness of $1.0 \mathrm{~mm}$ were subjected to tensile tests with a TS of $314.4 \mathrm{MPa}$ and 817.9 $\mathrm{MPa}$, respectively. Schmid, Suttner and Merklein have analyzed a draw bead that has a radius of $6.5 \mathrm{~mm}$ given a pressure of $5 \mathrm{MPa}$, where the strip (700 mm long and $50 \mathrm{~mm}$ wide) was pulled through the draw bead with a velocity of $10 \mathrm{~mm} / \mathrm{s}$ which shows microhardness values on the upper and lower layers of the sheet as a visualized for both sheet steels which overall increases of the hardness and strain [38].

\section{Materials and Methods}

The material used in aluminum alloy research is foil from serial AA1235 which has properties soft and ductile properties with a silver white luster and temper of H14.

Research methods consisting of the AA1235 with $\mathrm{TB}=300 \mu \mathrm{m}$ were used to form cups through micro deep drawing. Experiments were supported by a 3D FEM simulation. The mechanical properties of AA1235 were characterized through tensile tests after annealing with $\mathrm{TB}=70 \div 300 \mu \mathrm{m}$ to account for variation due to these size effects. Blanks were processed under (a) ARB 4 and 6 cycles, (b) combined ARB with AR and (c) postheat-treatment. The process was selected when a force $(F)$ from the simulation matched with the measured value.

ARB is a serial rolling that bonds some sheets due to a high thickness reduction. ARB is a cyclical rolling stack of sheet metals; a stack is sectioned into 2 halves, piled, and rolled again. Thickness reduction of the next rolling at least $50 \%$. The interface between the 2 surfaces was brushed by a steel brush, cleaned by Acetone, preheated at $200^{\circ} \mathrm{C}$ for 3 minutes and rolled immediately with a reduction of $65 \%$, which resulted in good bonding. $A$ rolls speed of $10 \mathrm{rpm}$ for ARB was selected. ARB started with 9 sheets, resulting in $9 \times 2 \times 2 \times 2=72$ layers for 4 cycles, and started with 13 sheets for 6 cycles, which yielded $13 \times 2 \times 2 \times 2 \times 2 \times 2=416$ layers. The purpose of $\mathrm{ARB}$ in this work is to obtain a reduction in the grain size of the material so that the forming of the material can be conducted at a thinner thickness.

$\mathrm{AR}$ is a process caused by modified rolling mills with different roll velocities, which creates a friction region between pairs of rolls. The speed ratio was set to 1:1.2, which corresponds to the highest true stress and true strain from Hadi [12]. The experimental apparatus consisted of an Instron machine and press tool for a cutting blank and a drawing cup, and is shown in Fig. 1. $\mathrm{F}$ (force) and $\mathrm{S}$ (stroke) data were recorded by a machine.

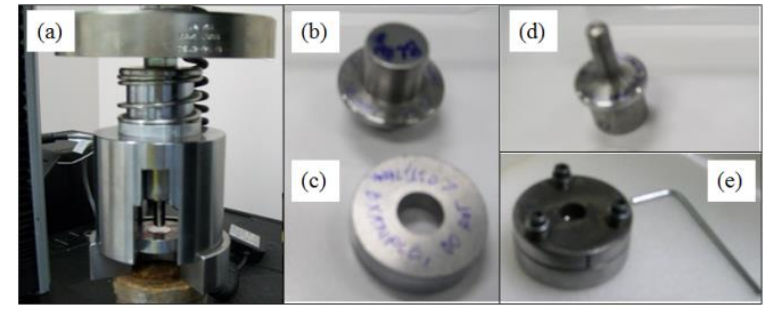

Fig. 1. A tool set of deep drawing: (a) a press tool mounted on an Instron testing machine, (b) a blanking punch, (c) a die block, (d) a drawing punch, and (e) a die set, for which the a blank holder included $3 \mathrm{~L}$ bolts and 3 compressive springs.

A simulated deep drawing of the cup was performed used FEM software, LS Dyna. The model consists of an AA1235 blank, a die, a punch, and a blank holder. The AA1235 model has a yield strength of $38 \mathrm{MPa}$ and a tensile strength (TS) of 74.2 MPa from Hadi et al. [11] with a diameter of blank $(\mathrm{DB})=14 \mathrm{~mm}$ and $\mathrm{TB}=300$ $\mu \mathrm{m}$ containing 28561 elements and 34693 nodes. The elements number in the 4 parts was 28561, which consisted of 10800 elements for the shell part and 17761 elements for the 3 solid tools. The number of integration points used in the deep drawing model is 8 points in the deformation area, namely between the contact surface of the bottom blank and the inner diameter surface of the die, and the integration points are from the edge of the blank to the punch corner radius.

Punch speed $(\mathrm{V})=100 \mathrm{~mm} / \mathrm{s}$ and FA (full annealing) conditions for all simulations by Hadi et al. [25].

The friction force $(\mathrm{F})$ and normal force $(\mathrm{N})$ on two contact areas on a sheet moving at a certain velocity were measured. The coefficient of friction was then calculated using the formula [39-40]:

$$
\mu=\mathrm{F} /(2 \mathrm{~N})
$$

The strip drawing test is used to measure the friction coefficient of AA1235 with lubrication on the sample surfaces, as shown in Fig. 2. 


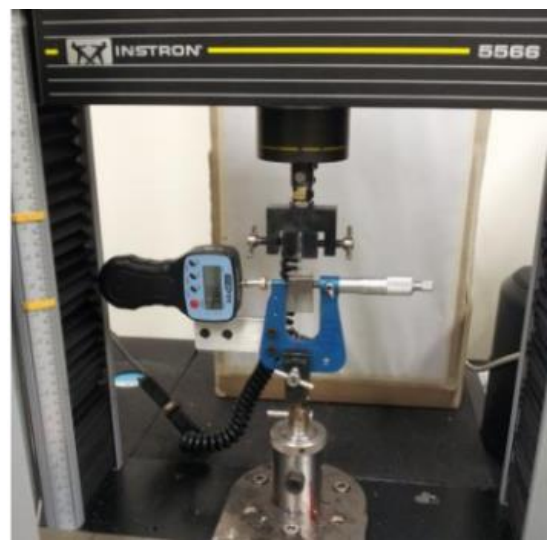

Fig. 2. The strip drawing test to measure the friction coefficient of AA1235.

The basics of the forming process, especially rolling and deep drawing, are discussed in the following description. Plates can be transformed into other shapes if a force is applied that exceeds the yield strength of a material. The yield strength is obtained from the tensile test results of a material that is achieved from the lowest load to the elastic limit that meets the requirements of Hooke's law. Formation in the case of rolling must be given a force that exceeds the yield strength of a material or enters the plastic region of a material. Hot rolling above the recrystallization temperature can be performed indefinitely, but cold rolling can only be conducted with a limited thickness reduction, if the reduction exceeds the formability limit, the material will crack or fracture. As a result of the rolling process, the strength of the material increases due to the strain hardening of the material. To anticipate that the material does not crack, an annealing process is required to eliminate residual stress due to the previous process. In the $A R B$ process, preheating is needed to help reduce the occurrence of side cracks in the rolling results. Similarly, for the deep drawing process, the stress-relieving process is conducted to reduce the possibility of cracks in the resulting cup, and with the stress relieving process the chance of cracking can be avoided, resulting in a cup without cracks or tears. Especially for micro deep drawing, the chance of wrinkling on the cup wall is very large. Generally, in the deep drawing process, the wrinkle is overcome by an advanced process, namely the ironing process. However, in this study, this process can be overcome by using a bulged punch where the size of the punch is made to start becoming larger when the wrinkle begins to occur, so that only one stroke in deep drawing can produce a cup without a wrinkle.

The method of eliminating wrinkles on the edge of the cup walls in the deep drawing process was granted for a patent on August 18, 2020, to the Ministry of Law and Human Rights of the Republic of Indonesia with the Number of Certificates of IDS000003125 for claims: the use of bulged punch in deep drawing can eliminate the occurrence of wrinkles in the cup wall, there is a thickening of the cup in the punch corner radius, and there is a reduction in the occurrence of earing on the edge of the cup wall.

\section{Results and Discussion}

Using ARB 6 cycles, $\mathrm{TB}=338 \mu \mathrm{m}$ and $\mathrm{DB}=14$ $\mathrm{mm}$ can form a cup with few wrinkles, but ARB 4 cycles failed, because it only reached a depth of $\sim 2.0 \mathrm{~mm}$. This means that ARB 6 cycles had a better form-ability than ARB 4 cycles. This was surprising because more ARB cycles produce materials with a lower ductility, but a higher strength according to Hadi et al. [11].

Cup drawing with ARB 6 cycles and AR 1 cycle with a speed ratio of 1:1.2 and an SR formed a cup without a tear but produced some wrinkles. The parameters were: clearance, $\mathrm{c}=0.057 \mathrm{~mm},(((8.26-7.54) / 2)-0.303)=0.057$ $\mathrm{mm}, \mathrm{DB} / \mathrm{TB}=14 \mathrm{~mm} / 303 \mu \mathrm{m}$, and diameter of die (DD) $/ \mathrm{DP}=8.26 / 7.54 \mathrm{~mm}$. For $\mathrm{DB}=14 \mathrm{~mm}, \mathrm{~TB}=$ $303 \mu \mathrm{m}$, the cup had edge wrinkles. A free $\mathrm{c}=0.057 \mathrm{~mm}$ is likely to produce a cup with wrinkles, but the material strength and ductility are adequate for deep drawing; then a minimum $\mathrm{c}$ is needed to produce a good cup and reduce wrinkles. The value of $\mathrm{c}$ relative to $\mathrm{TB}$ was $(0.057) / 0.303=19 \%$.

Some micro cups formed with ARB 6 cycles and AR 2 cycles from $\mathrm{TB}=45 \mu \mathrm{m}$ were produced according to Yu et al. [10].

Most deep drawings cause thickening of the cup edge if NP (normal punch) is used. The NP process used $\mathrm{TB}=0.05 \div 2 \mathrm{~mm}$, and the cup wall edge thickness was $0.105 \div 2.13 \mathrm{~mm}$, as a result, cup edge thickening was 5.2 $\div 56 \%$ from Hadi [12].

Using AA1235 with NP resulted in a thickening of $25.7 \%$, whereas BP resulted in $8.7 \%$; hence, BP was used to prevent wrinkles. Hadi [12] have researched deep drawing with thickening in the cup wall edge.

$\mathrm{BP}$ is a novel punch that was specifically designed (Fig. 3) by Hadi [12]. Novel BP exhibits a gradual curve from $\mathrm{DP}=7.59 \mathrm{~mm}$ to $\mathrm{DP}=7.70 \mathrm{~mm}$, which was used with $\mathrm{DD}=8.25 \mathrm{~mm}$ to draw a blank with $\mathrm{TB}=300 \mu \mathrm{m}$.

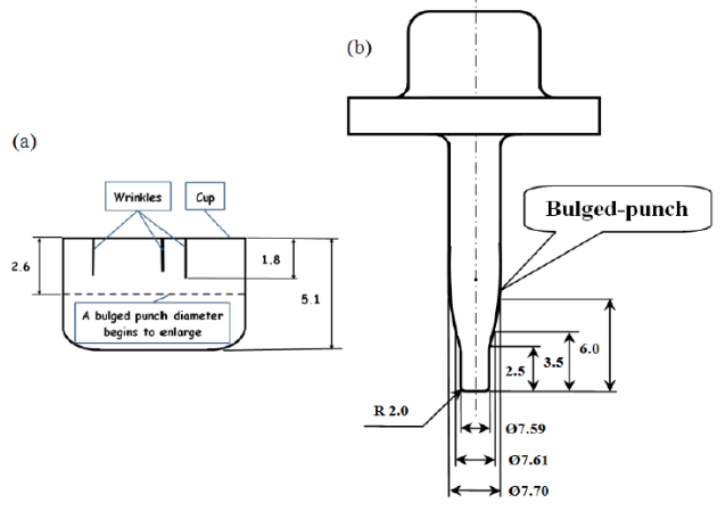

Fig. 3. Details of (a) a cup wrinkle depth, $1.8 \mathrm{~mm}$, and (b) the shape and size of a novel bulged punch for a blank of thickness $300 \mu \mathrm{m}$ and a die diameter of $8.25 \mathrm{~mm}$.

The friction coefficient of AA1235 with lubrication on the sample surfaces under full annealing (FA) conditions with a thickness of $300 \mu \mathrm{m}$ is shown in Fig. 4. 


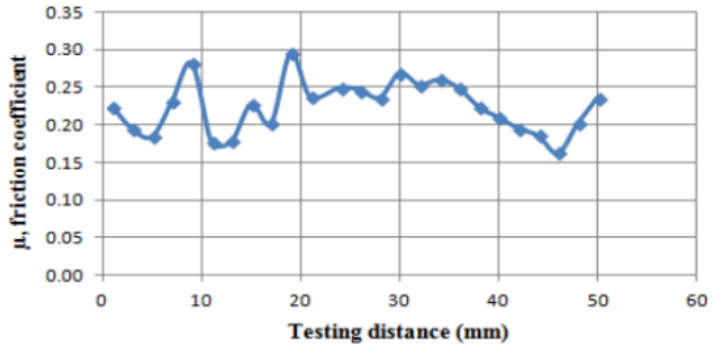

Fig. 4. The result of friction coefficient of the AA1235 with lubrication on the sample surfaces.

Friction coefficients $(\mu)$ of $0.10 \div 0.30$ were used for $\mathrm{TB}=300 \mu \mathrm{m}$ simulations, as shown in Fig. 5 from Hadi [12]. The range of $F$ was $F_{\text {max.sim.(0.10) }}=724 \mathrm{~N}$ to $\mathrm{F}_{\text {max.sim. }(0.30)}=1803 \mathrm{~N}$ and $\mathrm{F}_{\text {max.exp }}=1640 \mathrm{~N}$, which was $9 \%$ less than the simulated value. This discrepancy was due to ironing which affects the prevention of sidewall wrinkles according to Khademi et al. [5].

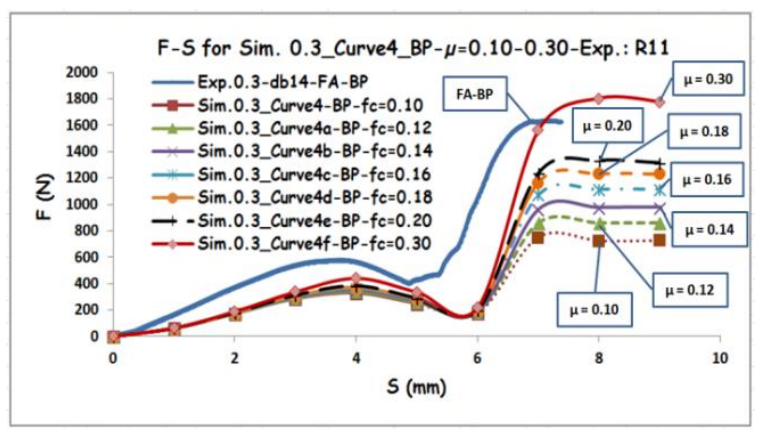

Fig. 5. The punch force (F)-punch stroke (S) for using a bulged punch with a coefficient of friction ranging from 0.10-0.30 for simulations with a blank thickness of 300 $\mu \mathrm{m}$ and FA condition.

The simulation result of AA1235 with $\mathrm{DB}=14 \mathrm{~mm}$, $\mathrm{TB}=0.3 \mathrm{~mm}, \mu=0.18, \mathrm{RP}=2.5 \mathrm{~mm}, \mathrm{RD}=1.2 \mathrm{~mm}$, $\mathrm{DP}=7.54 \mathrm{~mm}$, and $\mathrm{DD}=8.35 \mathrm{~mm}$ are shown in Fig. 6 by Hadi [12]. $\mathrm{F}_{\text {max.exp }}$ was $420 \mathrm{~N}, 17.3 \%$ greater than $\mathrm{F}$ in simulation with $\mu=0.18$ was found that $F_{\max . \operatorname{sim}}=358 \mathrm{~N}$; hence, a better prediction was obtained for $\mu=0.2$.

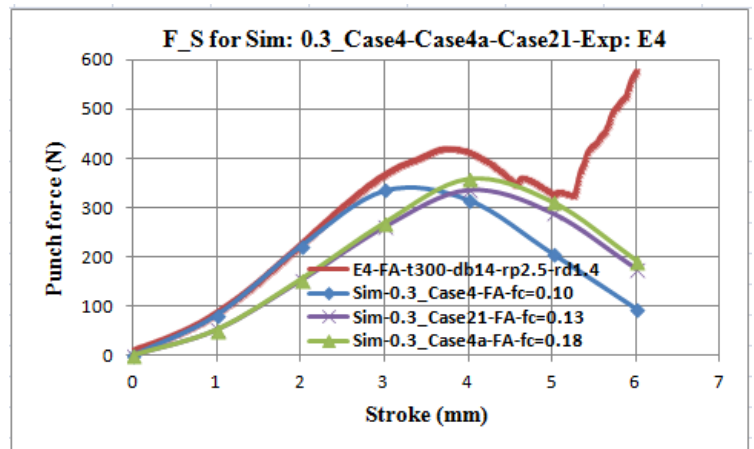

Fig. 6. The simulation results of deep drawing in the FA condition for a TB $=0.3 \mathrm{~mm}$.

The simulation result of AA1235 with $\mathrm{DB}=14 \mathrm{~mm}$, $\mathrm{TB}=0.13 \mathrm{~mm}, \mu=0.15, \mathrm{RP}=1.2 \mathrm{~mm}, \mathrm{RD}=1.2 \mathrm{~mm}$, $\mathrm{DP}=7.54 \mathrm{~mm}$, and $\mathrm{DD}=8.35 \mathrm{~mm}$ were compared to an $\mathrm{F}_{\text {max.exp }}$ of $440 \mathrm{~N}$, which was $20.23 \%$ greater than the
F simulation with $\mu=0.15$, which yielded $\mathrm{F}_{\text {max.sim }}=351$ $\mathrm{N}$; hence, a better prediction was obtained if $\mu=0.2$ was used, but the value was still $\sim 20 \%$ greater. F was lower because $\mathrm{c}$ at the cup top was wider for $\mathrm{TB}=0.13 \mathrm{~mm}$ than for $\mathrm{TB}=0.3 \mathrm{~mm}$, even though wrinkles occurred from Hadi [12].

The simulation results of $\mathrm{AA} 1235$ with $\mathrm{DB}=14$ $\mathrm{mm}, \mathrm{TB}=0.07 \mathrm{~mm}, \mu=0.1, \mathrm{RP}=1.2 \mathrm{~mm}, \mathrm{RD}=1.2$ $\mathrm{mm}, \mathrm{DP}=7.54 \mathrm{~mm}$, and $\mathrm{DD}=8.35 \mathrm{~mm}$ were $\mathrm{F}_{\text {max.sim }}=$ $67 \mathrm{~N}$. The curve decreased but then started to increase, due to the occurrence of wrinkles from Hadi [12].

$\mu$ can be estimated by matching $\mathrm{F}$ with the experimental results, but this is not simple because deep drawing is a complex process in which various parts of the blank experience tension, compression, and bending by RP and RD, and the blank holder presses onto the flange area to reduce the bending effect by Güner et al. [30].

SEM microstructural photos from annealing and AA1235 processed ARB for up to 4 cycles followed by stress relief at $200^{\circ} \mathrm{C}$ for $8 \mathrm{~h}$ which shows the deep drawing success of increasing the LDR of 1.869 to 2.003 which was never achieved by the AA1235 material, as shown in Fig. 7.
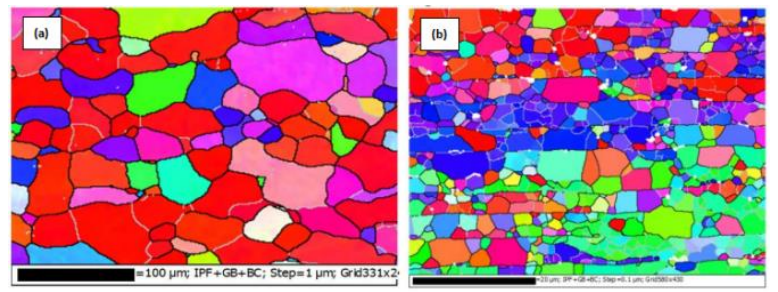

Fig. 7 The SEM of AA1235 for the electron back scatter diffraction (EBSD) images on the cross-section in the $\mathrm{RD}$ (a) of a FA material and (b) of an ARB 4 cycles material subsequent stress relieved at $200^{\circ} \mathrm{C}$ for $8 \mathrm{~h}$.

The effect of the annealing process is indicated by the results of the tensile test which represent its mechanical properties which show an increase from the AA1235 material which is only annealed with the tensile stress from $90 \mathrm{MPa}$ to $110 \mathrm{MPa}$ for the AA1235 material which is processed by ARB to 4 cycles followed by stress relief at $200^{\circ} \mathrm{C}$ for $8 \mathrm{~h}$.

The size effect of the SEM results on the annealing results of the AA1235 material with a grain size (d) of $25.09 \mu \mathrm{m}$ and the AA1235 material from the results of which were processed by an ARB up to 2 cycles producing $\mathrm{d}$ of $1.76 \mu \mathrm{m}$, followed by the ARB 4 cycle process producing $\mathrm{d}$ of $1.75 \mu \mathrm{m}$. With the continued stress-relieving process at $175^{\circ} \mathrm{C}$ for $8 \mathrm{~h}, \mathrm{~d}$ was coarsened to $1.77 \mu \mathrm{m}$, and for the stress-relieving process at $200^{\circ} \mathrm{C}$ for $8 \mathrm{~h}$, d was coarsened to $2.15 \mu \mathrm{m}$, as shown in Table 1 . 
Table 1. The result of average grain size (d) of the AA1235 from the SEM images.

\begin{tabular}{cccccccc}
\hline No. & $\begin{array}{c}\text { Treatment/ } \\
\text { process }\end{array}$ & $\begin{array}{c}\text { True } \\
\text { Stress } \\
(\mathrm{MPa})\end{array}$ & $\begin{array}{c}\text { Strain } \\
(\%)\end{array}$ & $\begin{array}{c}\mathrm{d} \\
(\mu \mathrm{m})\end{array}$ & $\begin{array}{c}\mathrm{d}_{\min } \\
(\mu \mathrm{m})\end{array}$ & $\begin{array}{c}\mathrm{d}_{\max } \\
(\mu \mathrm{m})\end{array}$ & $\begin{array}{c}\text { Number } \\
\text { of grains }\end{array}$ \\
\hline 1 & FA & 92 & 21 & 25.0 & 1.95 & 75.7 & 68 \\
& & & & 9 & & 5 & \\
2 & ARB1c & 140 & 2.53 & & & & \\
3 & ARB2c & 134 & 2.65 & 1.76 & 0.2 & 9.48 & 303 \\
4 & ARB3c & 134 & 2.65 & & & & \\
5 & ARB4c & 138 & 2.49 & 1.75 & 0.11 & 7.25 & 565 \\
6 & ARB4cSR175 & 85 & 3.6 & 1.77 & 0.2 & 9.20 & 535 \\
7 & ARB4cSR200 & 105 & 13.5 & 2.15 & 0.2 & 7.29 & 274 \\
\hline
\end{tabular}

In cup deep drawing, the grain orientation is uniformly formed around the cup circle, so that the orientation in all directions changes shape, the raw material is AA1235 after the ARB process is conducted for several cycles, followed by a stress-relieving process for up to $8 \mathrm{~h}$ at a temperature of $200^{\circ} \mathrm{C}$, so that after the blank is changed into a cup, there is no crack or tear in the cup corner, which means that the direction of rolling or grain orientation can be anticipated with further heat treatment after rolling. Components that are deep drawing processed include electronic component containers, e.g. capacitors and transistors, which are generally small in size and the material tends to be thinner.

The novelties of the present work are: (1) in overcoming the occurrence of a wrinkle, which is generally conducted in two steps, namely, the first process is deep drawing and the second process is ironing process, but by using a bulged punch, wrinkle can be eliminated in just one step from the deep drawing process, (2) in the cup corner, the result of deep drawing generally is that the thickness become thinner and the cup corner tends to tear, while in the present work with a one-step process using a bulged punch, the thickness of the cup corner become thicker, (3) the cup wall thickness resulting from the deep drawing process using a normal punch become thicker and the results from the use of a bulged punch show thinning that can facilitate the ejection of a product against the tools used, and (4) earing that occurs in the results of deep drawing of materials that were only fully annealed was greater than the earing that occurred in materials that were processed by ARB 4 cycles followed by stress relieving at $200^{\circ} \mathrm{C}$ for $8 \mathrm{~h}$, as shown in Fig. 8.

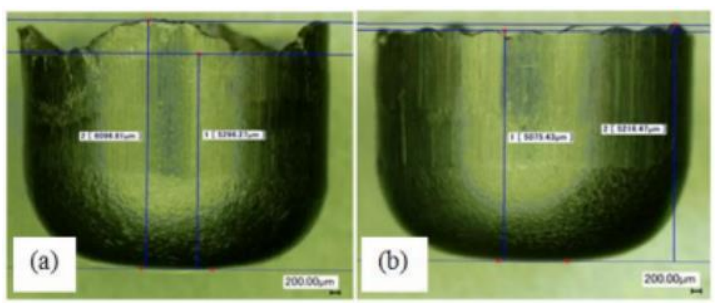

Fig. 8. The drawn cups by (a) a Normal Punch $(14.1 \%$ earing), and (b) a Bulged Punch (2.7\% earing).

In Fig. 9 from Hadi [12], the maximum Mises for $\mathrm{NP}$ and BP were quite different; the maximum stress on
RP of NP was $69 \mathrm{MPa}$ (Fig. 9(a)), compared to $63 \mathrm{MPa}$ for BP (Fig. 9(b)). This means that BP was lower, and hence the possibility of tearing was also lower. In the middle of the cup wall, stress with NP was the lowest (55 $\mathrm{MPa}$ ), which means that this region experienced less $\mathrm{F}$ than when $\mathrm{BP}$ was used $(76 \mathrm{MPa})$; the latter requires a high $\mathrm{F}$ to eliminate the wrinkles once they are initiated. The cup edge for NP showed a Mises $=85 \mathrm{MPa}$ (Fig. 9(a)) and only $55 \mathrm{MPa}$ (Fig. 9(b)) for BP. This means that $\mathrm{BP}$ was lower, and the cup edge was not thickened.

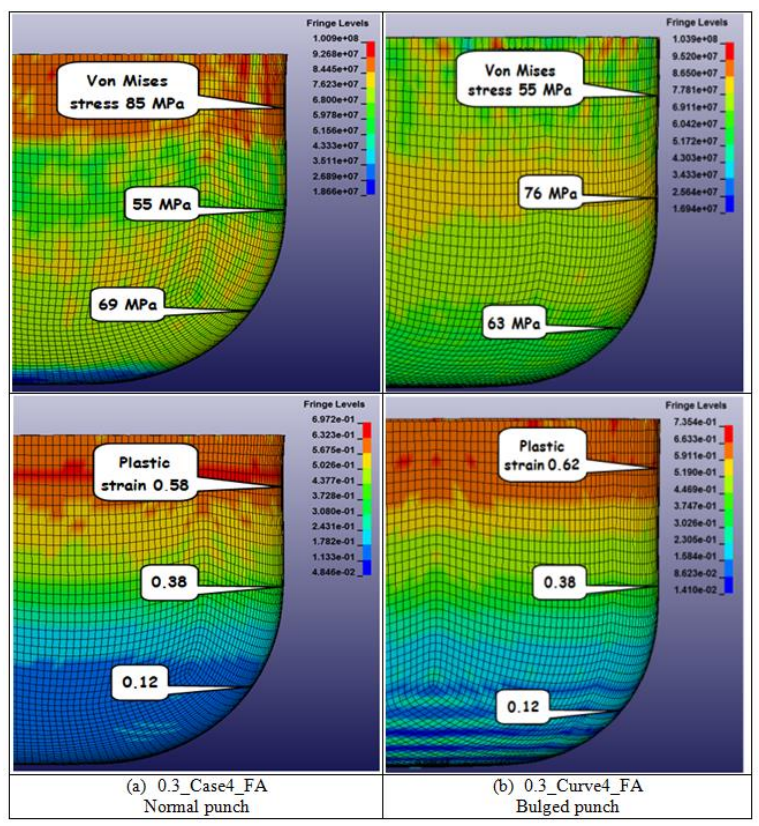

Fig. 9. The Von Mises stress (top figures) and a plastic strain (bottom figures) on AA1235 in the FA conditions for $\mathrm{a} \mathrm{TB}=300 \mu \mathrm{m}$ and $\mathrm{a} \mathrm{DB}=14 \mathrm{~mm}$ : (a) a NP and (b) a BP.

A comparison of the cup wall thickness in the experiment and simulation is shown in Fig. 10 from Hadi [12]. An experiment of AA1235 with $\mathrm{TB}=300 \mu \mathrm{m}$ and $\mathrm{DB}=14 \mathrm{~mm}$ exhibits a concave curve for NP (Exp.FA_20_NP) and a convex curve for BP (Exp.R11_BP). The simulation results reveal a concave curve for NP (Sim.0.3_Case1_FA_NP) and a concave curve for BP (Sim.0.3_Curve4_FA_BP). The limits of microforming capabilities can be neutralized by increasing the number of grains in the deformation zone, according to Dhal, Panigrahi and Shunmugam [14]. 

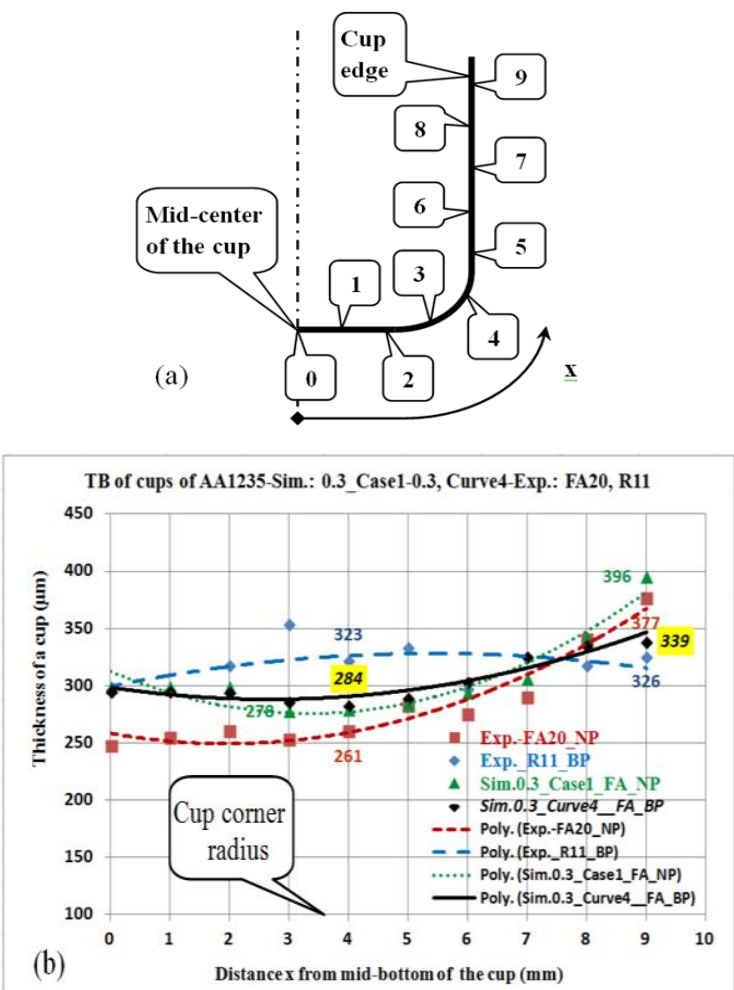

Fig. 10. A comparison of the distribution of the cup wall thickness in the experiment and the simulation results for the use of a NP and a BP for a blank thickness of $300 \mu \mathrm{m}$ and the FA condition.

From the results of the experiment, the thickness at $\mathrm{RP}$ using NP was $261 \mu \mathrm{m}$, and it was $323 \mu \mathrm{m}$ when using $\mathrm{BP}$; this indicates a significant thickening of $62 \mu \mathrm{m}$ $(23.8 \%)$. Thickening in this region is an advantage because it can reduce tearing. The cup edge thickness using NP was $377 \mu \mathrm{m}$, and it was $326 \mu \mathrm{m}$ when using BP which indicated a significant thickness reduction of 51 $\mu \mathrm{m}(13.5 \%)$.

The best value for the punch and die sizes is in the range of $4-15 \%$ c to TB to avoid wrinkles. For AA1235, NP resulted in a thickening of $25.7 \%$, and thickening of $8.7 \%$ when $\mathrm{BP}$ was used; therefore, $\mathrm{BP}$ was used to avoid wrinkles.

Simulations demonstrated that cup corner radius thickness was $270 \mu \mathrm{m}$ when NP was used and $284 \mu \mathrm{m}$ when $\mathrm{BP}$ was used; this finding indicated a thickening of $14 \mu \mathrm{m}(5.2 \%)$. The cup edge thickness for using NP was $396 \mu \mathrm{m}$, whereas it was $339 \mu \mathrm{m}$ when using BP; this indicated a thinning of $57 \mu \mathrm{m}$ (14.4\%), which helps the cup to be ejected from tools more easily. Predictions were made on thinning, wrinkling, and spring-back defects in deep drawing by Takalkar and Chinnapandi [3]. Multistage deep drawing can predict thinning and wrinkling by Takalkar and Babu [15].

Figure 6 shows the simulation results that more $\mathrm{c}$ resulted in more wrinkles; for thinner blank, the wave of wrinkles was consequently higher.

An improvement was attempted by SR, and the material was then deeply drawn, resulting in a very good cup when $\mathrm{DB}=15 \mathrm{~mm}$ was used with an $\mathrm{LDR}$ was 2.003. This finding is extraordinary for a one-step deepdrawing because the most successful one-step deep drawing has LDR $<2$, such as a fully drawn cup of AA6111 with an LDR of 1.752 by Reddy and Rajesham [21]. ARB 6 cycles and AR 2 cycles with TB $=45 \mu \mathrm{m}$ and SR can form cups without tears, even though it had some wrinkles. The advantages of using BP compared with using NP are shown in Table 2.

Table 2. The advantages of using a BP compared with a NP for the deep drawing process.

\begin{tabular}{|c|c|c|c|}
\hline \multicolumn{2}{|c|}{ No. Advantages } & \multirow[b]{2}{*}{$\begin{array}{l}\text { In experiment } \\
\\
\text { No wrinkles } \\
\text { on blank } \\
\text { thickness } 300 \\
\mu \text { m of blank of } \\
4 \text { cycles ARB } \\
\text { followed by } \\
\text { SR at } 200^{\circ} \mathrm{C} \\
\text { for } 8 \mathrm{~h} .\end{array}$} & \multirow[b]{2}{*}{\begin{tabular}{l}
\multicolumn{1}{c}{ In simulation } \\
No wrinkles for \\
blank thickness of \\
$300 \mu \mathrm{m}$ due to \\
have changed to \\
the thickening on \\
the cup edge. Half \\
part $(\sim 50 \%)$ \\
wrinkles on wall \\
height were \\
occurred at the \\
cup wall edge for \\
blank thickness \\
$130 \mu \mathrm{m}$, and \\
whole wrinkle of \\
the cup wall for \\
blank thickness
\end{tabular}} \\
\hline 1 & $\begin{array}{l}\text { Preventing } \\
\text { the } \\
\text { formation } \\
\text { of cup } \\
\text { wrinkles }\end{array}$ & & \\
\hline 2 & $\begin{array}{l}\text { Reducing } \\
\text { the } \\
\text { occurrenc } \\
\text { e of cup } \\
\text { earing }\end{array}$ & $\begin{array}{l}\text { About } 80^{\circ} \% \\
\text { lower earing of } \\
\text { blank of } 4 \\
\text { cycles ABR } \\
\text { followed by } \\
\text { SR at } 200^{\circ} \mathrm{C} \\
\text { for } 8 \mathrm{~h} \text { than } \\
\text { FA condition. }\end{array}$ & $70 \mu \mathrm{m}$ \\
\hline 3 & $\begin{array}{l}\text { Increasing } \\
\text { the cup } \\
\text { wall } \\
\text { thickness } \\
\text { of the } \\
\text { punch } \\
\text { corner } \\
\text { radius }\end{array}$ & $\begin{array}{l}\text { The significant } \\
\text { thickening of } \\
62 \mu \mathrm{m}(23.8 \%) \\
\text { of thickness } \\
\text { on the cup } \\
\text { corner radius } \\
\text { when using a } \\
\text { BP was } 323 \\
\mu \mathrm{m} \text { than } 261 \\
\mu \mathrm{m} \text { thick when } \\
\text { using a NP. }\end{array}$ & $\begin{array}{l}\text { The quite } \\
\text { thickening of } 14 \\
\mu \mathrm{m}(5.2 \%) \text { when } \\
\text { using a BP, the } \\
\text { thickness on the } \\
\text { cup corner radius } \\
\text { when using a BP } \\
\text { was } 284 \mu \mathrm{m} \text { than } \\
270 \mu \mathrm{m} \text { thick } \\
\text { when using a NP. }\end{array}$ \\
\hline 4 & $\begin{array}{l}\text { Reducing } \\
\text { the cup } \\
\text { edge } \\
\text { thickness }\end{array}$ & $\begin{array}{l}\text { The significant } \\
\text { reduction in } \\
\text { thickness on } \\
\text { the cup edge } \\
\text { of } 51 \mu \mathrm{m} \\
(13.5 \%) \text { was } \\
326 \mu \mathrm{m} \text { when } \\
\text { using a BP } \\
\text { than } 377 \mu \mathrm{m} \\
\text { thick when } \\
\text { using a NP. }\end{array}$ & $\begin{array}{l}\text { The significant } \\
\text { thinning on the } \\
\text { cup edge of } 57 \\
\mu \mathrm{m}(14.4 \%) \text { was } \\
339 \mu \mathrm{m} \text { when } \\
\text { using a BP than } \\
\text { was } 396 \mu \mathrm{m} \text { thick } \\
\text { when using a NP. }\end{array}$ \\
\hline
\end{tabular}




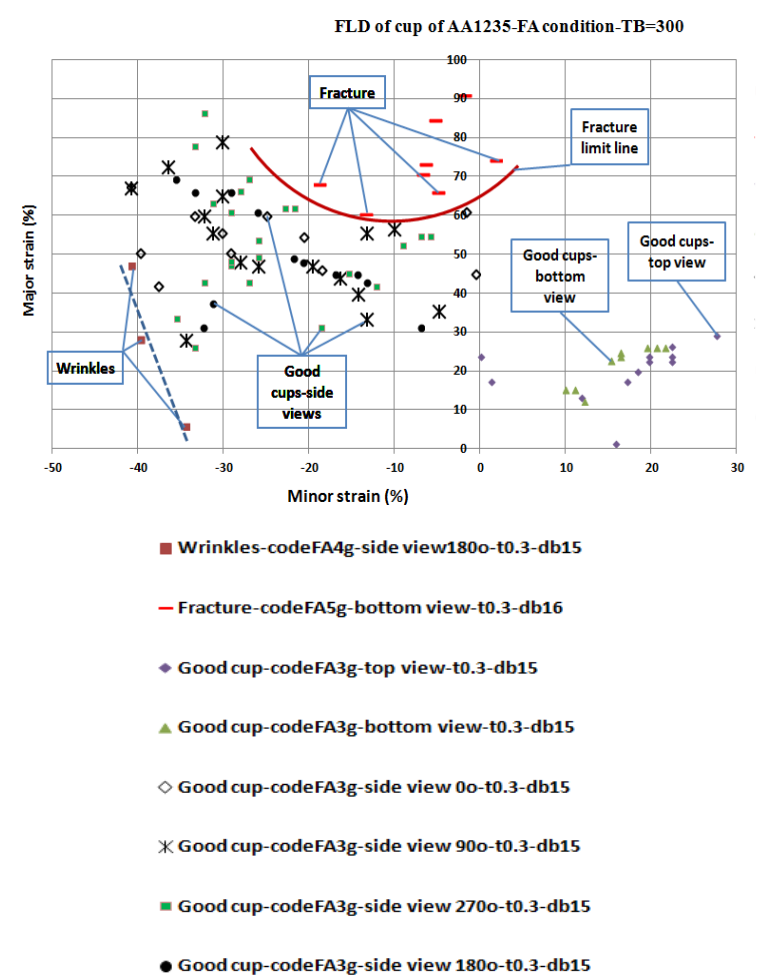

Fig. 10. The forming limit diagram (FLD) of an AA1235 deep drawn cup.

FLD of a deep-drawn cup from AA1235 was analyzed (Fig. 10) by Hadi [12]. Good cups were obtained under the fracture limit line, and the fracture cups were obtained above the fracture limit line.

Verification of the model in this paper is by experimenting in deep drawing using a bulged punch on AA1235 material with a heat treatment process only with full annealing conditions compared to AA1235 material which was conducted by the ARB process followed by stress relieving at a temperature of $200^{\circ} \mathrm{C}$ for $8 \mathrm{~h}$. The proof that only one stroke in deep drawing can eliminate the occurrence of wrinkle is shown from the measurement results of the experiment with thinning of the wall thickness and thickening of the cup corner was supported by the simulation results.

\section{Conclusions}

Experimental and simulation results of AA1235 for $\mathrm{TB}=300 \mu \mathrm{m}$ yielded the following conclusions:

1) BP can eliminate wrinkles by ironing in the latter part of the stroke. This proposed BP can produce a good cup without wrinkles. Other benefits of the BP method compared to NP include (a) thickening of the cup corner radius, (b) thinning of the cup edge, and (c) reduced earing.

2) Earing can be reduced by ARB 4 cycles following SR before deep drawing. For FA conditions, using BP on $\mathrm{TB}=300 \mu \mathrm{m}$ may decrease earing on a cup, but $\mathrm{F}$ on $\mathrm{BP}$ is $181 \%$ greater than on NP, due to ironing.

3) Cup thickness at RP thickened when BP was followed by NP. The cup edge was thicker when NP was used, but it decreased almost to initial TB when BP was used. A cup edge thickness reduction of $13.5 \%$ due to ironing when BP was used is significant for facilitating cup removal from tools.

4) Values of $\mu=0.18 \div 0.23$ in micro cup drawing can be estimated by matching $\mathrm{F}$ between theory and experiment.

5) In the simulations of $\mathrm{TB}=300 \mu \mathrm{m}$ for $\mathrm{AA1235}$, all cups were perfect, without tears/wrinkles; however, for $\mathrm{TB} \leq 130 \mu \mathrm{m}$, the cup wall exhibited a greater tendency to wrinkle.

\section{Acknowledgement}

This work was supported by Central Government of Republic of Indonesia and State Polytechnic of Malang, Indonesia [B-/3395/Setneg/Setmen/KTLN/07/2009]. The authors thank Stuart Rodd, Andrew Scobie, and Joe Abbott from the University of Wollongong, Australia for producing a press-tool and rolling the samples.

\section{References}

[1] R. Sridhar, S. Inbarasan, R. Ramkumar, and S. C. Siva, "Review on micro deep drawing process for thin foil materials," Int. J. of Innov. in Eng. and Tech., vol. 11, no. 3, pp. 10-14, Oct. 2018.

[2] C. Bell, J. Corney, N. Zuelli, and D. Savings, "A state of the art review of hydroforming technology, its applications, research areas, history, and future in manufacturing," Int. J. Mater. Form., vol. 13, pp. 789828, Dec. 2019.

[3] A. S. Takalkar, and L. B. M. Chinnapandi, "A review on effect of thinning, wrinkling and spring-back on deep drawing process," Part B: J of Eng Manuf, vol. 233, no. 4, pp. 1011-1036, Feb. 2018.

[4] N. Srinivasan, D. Rajenthirakumar, and R. Sridhar, "Micro forming-key issues and research opportunities," Adv. in Nat. and Appl. Sci., vol. 11, no. 4, pp. 557-579, Feb. 2018.

[5] M. Khademi, A. Gorji, M. Bakhshi, and M. S. Yazdi, "Investigation of wrinkling in hydrodynamic deep drawing assisted by radial pressure with inward flowing liquid," in Proceedings of the 17th International Conference on Sheet Metal, Palermo, Italy, 2017, pp. 6570.

[6] Z. A. Mahmood, I. K. Irthiea, and A. K. Ahmed, "Optimization of initial blank shape for flexible micro deep drawing of square parts," Mater TodayProc., vol. 20, no. 4, pp. 555-559, Oct. 2020.

[7] D. Z. Lubis and I. Ristiawan, "Blanking clearance and punch velocity effects on the sheared edge characteristic in micro-blanking of commercially pure copper sheet," J Mech Sci Technol., vol. 1, no. 2, pp. 53-60, Nov. 2017.

[8] R. Pan, J. Zheng, Z. Zhang, and J. Lin, "Cold rolling influence on residual stresses evolution in heattreated aa7xxx T-section panels," Mater Manuf Process, vol. 34, no. 4, pp. 431-446, Nov. 2018. 
[9] M. Akhtar, S. Z. Qamar, M. Muhammad, and A. Nadeem, "Optimum heat treatment of aluminium alloy used in manufacturing of automotive piston components," Mater Manuf Process, vol. 33, no. 16, pp. 1874-1880, Dec. 2018.

[10] H. Yu, A. K. Tieu, S. Hadi, C. Lu, A. Godbole, and C. Kong, "High strength and ductility of ultra thin laminate foils using accumulative roll bonding and asymmetric rolling," Metal and Mater Trans. A., vol. 46, no. 2, pp. 869-879, Nov. 2014.

[11] S. Hadi, A. K. Tieu, C. Lu, and H. T. Zhu, "A micro deep drawing of ARB processed aluminium foil AA1235," Int. J. of Mat. and Prod. Tech., vol. 47, no. 14, pp. 175-187, Jan. 2013.

[12] S. Hadi, "Micro deep drawing of aluminium foils AA1235," Ph.D. Dissertation, Univ. of Wol., NSW, Australia, 2014.

[13] Z. H. Mahmood, I. K. Irthiea, and K. A. Abed, "Experimental and simulation investigations of micro flexible deep drawing using floating ring technique," Al-Khwarizmi Eng. J., vol. 14, no. 3, pp. 20-31, Dec. 2018.

[14] A. Dhal, S. Panigrahi, and M. S. Shunmugam, "Investigation into the micro deep drawing capabilities of a specially engineered refined aluminium alloy," in Proceedings of the International Conference on New Forming Technology, Bremen, Germany, vol. 190, no. 2, 2018, Paper 10001.

[15] A. S. Takalkar and M. C. L. Babu, "Multi-stage deep drawing process of axis-symmetric extra deep drawing steel cylindrical cup," Eng. Res. Express, vol. 2, pp. 1-16, Apr. 2020.

[16] L. Luo, Z. Jiang, D. Wei, X. Wang, C. Zhou, and Q. Huang, "Micro-hydromechanical deep drawing of metal cups with hydraulic pressure effects," Frontiers of Mech. Eng., vol. 13, no. 1, pp. 66-73, Jan. 2018.

[17] G. Wang, Y. Li, S. Liu, J. Yang, and M. Yang, "Micro deep drawing of T2 copper foil using proportional decreased tools," The Int. J. of $A d v$. Manuf. Tech., vol. 95, no. 1-4, pp. 277-285, Oct. 2017.

[18] H. Sato, K. Manabe, T. Furushima, D. B. Wei, Z. J. Jiang, and S. Alexandrov, "On the scale dependence of micro hydromechanical deep drawing," Key Eng. Mat., vol. 725, pp. 689-694, Dec. 2016.

[19] T. Intarakumthornchai, S. Jirathearanat, S. Thongprasert, and P. Dechaumphai, "FEA based optimization of blank holder force and pressure for hydromechanical deep drawing of parabolic cup using 2-D interval halving and RSM methods," Eng. J., vol. 14, no. 2, pp. 15-32, Apr. 2010.

[20] L. T. Thanh, B. T. Long, T. T. Van, and N. D. Toan, "A study on deep-drawing process with two shaping states for a fuel-filler cup using combined simulation and experiment," Adv Mech Eng., vol. 11, no. 8, pp. 1-11, Aug. 2019.

[21] A. C. S. Reddy, and S. Rajesham, "Determination of LDR in deep drawing using reduced number of blanks," Mater Today-Proc., vol. 5, no. 13, pp. 2713627141, 2018.
[22] V. R. Shinge, and U. A. Debade, "Experimental investigation on forming limit diagram of mild carbon steel sheet," Proc. Manuf., vol. 20, pp. 141146, Feb. 2018.

[23] C. Sudarsan, K. H. Banker, S. Hazra, R. Bhagat, and S. K. Panda, "Experimental investigations on forming limit diagram of ultra thin SS 304 steel: effect of circular grid size, sheet orientation, punch size and deformation speed," Adv. in Mat. and Pro. Tech., vol. 5, no. 1, pp. 25-38, Aug. 2018.

[24] Z. Sheng, and P. Mallick, "Predicting forming limit curve using a new ductile failure criterion," $S A E$ Tech. Paper, 2017.

[25] M. A. Woo, W. J. Song, B. S. Kang, and J. Kim, "Acquisition and evaluation of theoretical forming limit diagram of $\mathrm{Al}$ 6061-T6 in electrohydraulic forming process," Metals, vol. 9, no. 401, pp. 1-15, Apr. 2019

[26] F. Zhalehfar, R. Hashemi, and S. J. Hosseinipour, "Experimental and theoretical investigation of strain path change effect on forming limit diagram of AA5083." Int. J. Adv. Manuf. Technol., vol. 76, pp. 1343-1352, Sep. 2014.

[27] D. Rahmatabadi, and R. Hashemi, "Experimental evaluation of forming limit diagram and mechanical properties of nano/ultra-fine grained aluminum strips fabricated by accumulative roll bonding," Int. J. of Mat. Res., vol. 108, pp 1-9, Oct. 2017.

[28] E. A. Alisaraei, R. Hashemi, D. Rahmatabadi, and C. Sommitsch, "Experimental study of forming limit diagram and mechanical properties of aluminum foils processed by the accumulative roll bonding," Mater. Res. Express, vol. 7, no. 126511, pp. 1-11, Nov. 2020.

[29] S. Hadi, H. L. Yu, K. Tieu, and C. Lu. "Simulation of defects in micro-deep drawing of an aluminium alloy foil," in AIP Conference Proceedings, vol. 1532, pp. 298-303, May 2013.

[30] A. Güner, M. Gösling, I. Burchitz, and B. Carleer, "Experimental and numerical investigation of ironing in deep drawn parts," J. of Physics, vol. 1063, no. 1, pp. 1-6, Jul. 2018.

[31] A. Mashalkar, G. Kakandikar, and V. Nandedkar, "Micro-forming analysis of ultra-thin brass foil," Mat. and Manuf. Pro., vol. 34, no. 13, pp. 1-7, Aug. 2019.

[32] N. Guo, C. Y. Sun, and M. W. Fu, "Size effect affected deformation characteristics in micro deep drawing of TWIP domed-bottom cups," Procedia Eng., vol. 207, pp. 2072-2077, Sep. 2017.

[33] L. Luo, Z. Jiang, and D. Wei, "Influences of microfriction on surface finish in micro deep drawing of SUS304 cups," Wear, vol. 374-375, pp. 36-45, Mar. 2017.

[34] C. B. Zhang, and F. Gong, "Deep drawing of cylindrical cups using polymer powder medium based flexible forming," Int. J. of Precision Eng. and Manuf.-Green Tech., vol. 5, no. 1, pp. 63-70, Feb. 2018. 
[35] T. Trzepiecinski, R. Fejkiel, and A. Kubit, "Experimental evaluation of drawbead coefficient of friction," Acta Met. Slovaca, vol. 23, no. 4, pp. 337344, Dec. 2017.

[36] H. Schmid, and M. Merklein, "Effect on the mechanical properties of sheet metals after the use of draw beads in deep drawing," in Proceedings of the International Conference on New Forming Technology, MATEC Web of Conferences, Bremen, Germany, vol. 190, Jan. 2018, Paper 05001

[37] E. Bassoli, A. Sola, L. Denti, and A. Gatto, "Experimental approach to measure the restraining force in deep drawing by means of a versatile draw bead simulator," Mat. and Manuf. Pro., vol. 34, no. 11, pp. 1-10, Jun. 2019.
[38] H. Schmid, S. Suttner, and M. Merklein, "An incremental analysis of a deep drawing steel's material behaviour undergoing the predeformation using draw beads," J. of Physics, vol. 896, pp. 1-6, Jul. 2017.

[39] B. Guo, F. Gong, C. Wang, and D. Shan, "Size effect on friction in scaled down strip drawing," $J$. Mater. Sci., vol. 45, pp. 4067-4072, Apr. 2010.

[40] V. Severo, L. Vilhena, P. N. Silva, J. P. Dias, D. Becker, S. Wagner, and A. Cavaleiro, "Tribological behaviour of W-Ti-N coatings in semi-industrial strip-drawing tests," J. of Mat. Pro. Tech., vol. 209, no. 10, pp. 4662-4667, Nov. 2008.

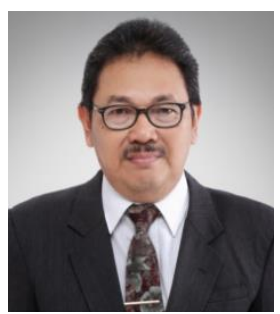

Syamsul Hadi was born in Malang, East Java, Indonesia in 1959. He received the B.S. degree in energy conversion from the Sepuluh Nopember Institute of Technology, Surabaya, Indonesia in 1989, M.S. degree in science and engineering materials from Bandung Institute of Technology, Bandung, Indonesia in 1997 and Ph.D. degree in mechanical, materials, and mechatronics engineering from University of Wollongong, New South Wales, Australia in 2014 with the focus on research area of micro deep drawing of Aluminium foil AA1235.

$\mathrm{He}$ is currently the Senior Lecturer in Department of Mechanical Engineering, State Polytechnic of Malang, Malang, Indonesia since 2004. From 2019 until now, he was a Head of Study Program in Applied Master of Manufacture Technology Engineering in Department of Mechanical Engineering, State Polytechnic of Malang, Malang, Indonesia. He is the author of 3 books, more than 33 articles, and more than 3 inventions. His research interests include deep drawing, fatigue testing of material, material testing, electroplating, and manufacturing processes. He is a Reviewer of IEEE Access Journal articles, Journal of Engineering Research and Report and holds four Indonesian Patents. He has a member of The Minerals, Metals \& Materials Society (TMS), USA with the membership number 513045.

Dr. Hadi was a recipient of the research funding of fatigue testing development for the years of 2021-2023 from Ministry of Education, Culture, Research, and Technology of the Republic of Indonesia and has h-index of Scopus: 4, and Author ID: 56550088400.

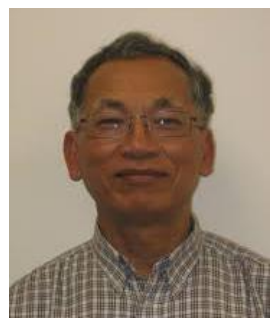

Anh Kiet Tieu received his Ph.D. from the University of Western Australia. He led the Technical Investigations section at BlueScope Steel for eight years and currently is a Professor of Mechanical Engineering at the University of Wollongong, Australia, since 1982.

$\mathrm{He}$ is a Fellow of the Academy of Technological Sciences and Engineering. His areas of interest: Rolling technology, Micro forming, Tribology, and Computational mechanics in metal forming. He has many years' experiences as academic and successfully supervised many Masters and $\mathrm{PhD}$ students.

Senior Prof. Tieu also published some papers in international journals and has h-index of Scopus: 37, Author ID: 7006165349.

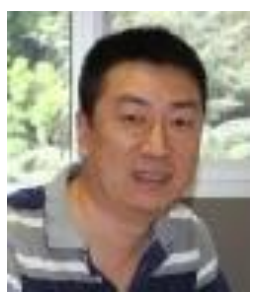

Cheng Lu has worked at the University of Wollongong (UOW) for six teen years and Northeastern University (NEU), China for four years since graduating with a PhD from the NEU and currently is an Associate Professor of Mechanical Engineering at the University of Wollongong, Australia.

His areas of interest: Rolling technology, Energy pipeline, Fabrication of ultra-fine grained materials, Texture modeling, and Molecular dynamics simulation.

A/Prof. Lu developed the first version of the pipeline fracture control software EPDECOM. $\mathrm{He}$ has many years' experiences as academic and successfully supervised many Masters and $\mathrm{PhD}$ students. $\mathrm{He}$ currently serves as a Program Leader in the Cooperative Research Centre for Energy Pipeline. A/Prof. Lu has published a total of more than 190 international papers, has 2 patents, and has h-index of Scopus: 33, Author ID: 7404805151. 


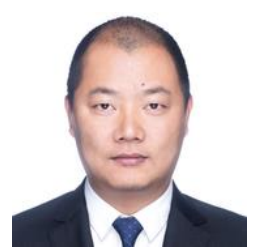

Hailiang Yu, Research Fellow, University of Wollongong; Professor, Shenyang University. Areas of interest: Modelling and simulation in metal forming; Metal forming process; Quality control of rolled steel in production; Wear of materials in metal forming and manufacturing; Foundry and heat treatment of metal materials. Professional information: Editor-In-Chief, Modeling and Numerical Simulation of Materials Science Conference Co-Secretariat, 15 th International Conference on Advances in Materials \& Processing Technologies, AMPT 2012, University of Wollongong, Australia, September 2012. Scientific Committee, The 11th International Conference on Numerical Methods in Industrial Forming Processes, NUMIFORM 2013, Shenyang Liaoning, China, July 2013. He is reviewers of some international journals and also published some papers in international journals and has h-index of Scopus: 22, Author ID: 56112925200.

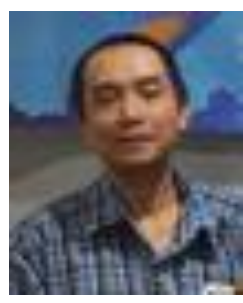

Alain Kusmoko received his PhD degree in the School of Mechanical, Materials and Mechatronics Engineering, University of Wollongong, Australia in 2016 with the focus on research area of Effect of laser power and steel and nickel-based alloy substrates on hardness and wear resistance of laserdeposited Stellite coatings and works as a Research Fellow in School of Mechanical, Materials and Mechatronics Engineering, Faculty of Engineering and Information Sciences, University of Wollongong, Australia since 2016.

He also published some papers in international journals and has h-index of Scopus: 2, Author ID: 25823154600. His research area includes Materials engineering, Surface morphology and Wear analysis, and Surface engineering. He ever presented some papers in 2014 on International Conference on Mechatronics and Mechanical Engineering (ICMME), Chengdu, China; in 2014 on $6^{\text {th }}$ International Conference on Mechanical and Electrical Technology (ICMET), Bangkok, Thailand; in 2014 on $5^{\text {th }}$ International Conference on Key Engineering Materials (ICKEM), Bali, Indonesia; in 2013 on International Conference on Advanced Materials Science and Technology (ICAMST), Yogyakarta, Indonesia; in 2012 on 15 th International Conference on Advanced Materials and Processing Technologies (AMPT), Wollongong, Australia; and invited to attend in 2001 at Institute of Materials Research at GKSS Research Center Geesthacht, Hamburg-Germany, as Scientific Guest. Mr. Kusmoko is an active participate in numerous seminar and conferences in the field area of interest.

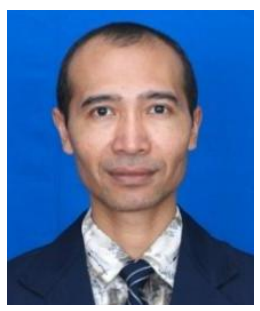

Anggit Murdani received his Doctor of Engineering degree from the University of the Ryukyus, Japan, in 2009. He is currently a Senior Lecturer with the Department of Mechanical Engineering, State Polytechnic of Malang, Indonesia. He is also the ever as a Head of Center of Research and Community Service and now he is a Vice Director 3 of student activities at the same institution. He engages actively in several research projects. He received two research grants from Ministry of Research, Technology and Higher Education, Indonesia, in 2014 and 2016. He also received short term fellowship from Japan Student Service Association for 3 months in 2015.

Dr. Murdani actively participates in national and international conferences, workshops, and scientific forums. He published several papers in reputable international journals. His Scopus Author ID is 12790361100 and $h$-index is 5 . He is a Reviewer for some national and international journals. His research area includes Fatigue Behavior of Materials, Strength of Materials, Fracture Mechanics, and Composite Materials.

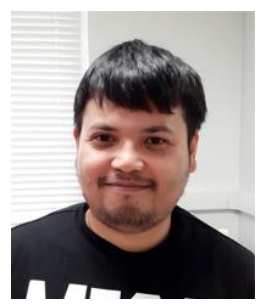

Dianta Ginting received his Bachelor in Geophysics from the Bandung Institute of Technology, Bandung, Indonesia, in 2007, Master of Physic degree from Chungbuk National University, SouthKorea, in 2013. His PhD degree from Kyung Hee University, South-Korea in 2018 with the focus on research thermoelectric materials. He has published article to his research interest in international refereed journal and has h-index of Scopus: 8, Author ID: 55579353500.

His research interest includes Magnetic Material (Peroskite materials, Phase transition of magnetic material, Critical behavior of magnetic materials), Semiconductor and Thermoelectric materials (material based on $\mathrm{PbTe}, \mathrm{PbSe}$, and $\mathrm{PbS}$ ) and Crystal topological insulators. 